\title{
MODELAGEM ANALÍTICA APLICADA À NEGOCIAÇÃO E DECISÃO EM GRUPO
}

\author{
Carlos Francisco Simões Gomes \\ Faculdades IBMEC-RJ \\ Rio de Janeiro - RJ \\ simoes@,casnav.mar.mil.br
}

Recebido em 07/2005; aceito em 07/2006 após 1 revisão Received July 2005; accepted July 2006 after one revision

\begin{abstract}
Resumo
A obtenção do consenso em uma negociação e/ou decisão em grupo é um problema complexo que envolve vários agentes, critérios, alternativas, interesses, pontos de vista conflitantes e grupos de pressão. Neste contexto, imprecisão e riscos estão presentes. Ferramentas que tratem imprecisões e/ou indiscernibilidades e sistemas de apoio à decisão e/ou negociação podem e devem ser utilizadas para facilitar a obtenção de um consenso. Este artigo, após uma revisão de algumas Metodologias Analíticas, mostra como usar estas metodologias com o propósito de reduzir os conflitos, minimizando o tempo de negociação e buscando o consenso.
\end{abstract}

Palavras-chave: negociação; decisão em grupo; apoio multicritério à decisão.

\begin{abstract}
Trying to reach a consensus in a negotiation or decision process can be a very complex problem involving multiple agents, different criteria, alternatives, conflicting points of view and pressure groups, etc. In this context uncertainty and risk are quite often present. Tools for imprecision analysis and group decision aiding or negotiation can be thus used in order to facilitate achieving a compromise. This article, after a summary review, shows how to use some methodologies in order to minimize conflicts and negotiation time trying to achieve a consensus.
\end{abstract}

Keywords: negotiation; group decision; multicriteria decision aid. 


\section{Introdução}

Quando existe o interesse na busca da solução de um problema que atinge os atores de decisão, estes se envolvem em decisões em grupo, seja inter-organizações seja intraorganizações, ou mesmo entre sindicatos, bem como Estados soberanos etc. Para tal, estas pessoas, ou centros de decisão, a partir de agora denominadas de atores da decisão/ negociação ou simplesmente atores, juntam-se em grupos. Estes atores durante a decisão em grupo ou negociação devem buscar segundo Leya-López \& Fernandez-González (2003) que:

- as preferências individuais sejam convertidas em decisão coletiva;

- a decisão final dos grupos envolvidos seja produto das preferências e informações individuais dos atores de decisão envolvidos.

Atualmente o Engenheiro de Produção tem a seu dispor uma vasta gama de conceitos e procedimentos (ferramentas, técnicas, algoritmos e metodologias) da Pesquisa Operacional (PO) e da Engenharia de Sistemas, que podem ser úteis no suporte à negociação.

Sob esse aspecto, deve-se destacar o desenvolvimento dos denominados Sistemas de Suporte à Negociação (SSN), tanto na vertente informática como na analítico-matemática (Gomes \& Gomes, 1996; Gomes, Gomes \& Moreira, 1998).

Para Dias (2000) o apoio à decisão busca os valores precisos e para tal freqüentemente utiliza-se das seguintes questões:

(a) Existe consenso entre os decisores acerca de um valor?

(b) É possível utilizar-se da votação para resolver o impasse?

(c) Pode-se fazer uma média (aritmética ou geométrica) para buscar um "meio-termo"?

(d) É conhecido algum valor futuro?

(e) Podem-se fazer estimativas?

(f) Podem-se vislumbrar cenários futuros?

(g) Existe hesitação sobre o "peso" de um ou mais critérios?

(h) É possível criar-se um questionamento que ajude a elicitação destes valores?

(i) Será arbitrado um valor para o início do debate?

(j) Fez-se uma análise de sensibilidade dos valores utilizados?

(k) Quais as Teorias que tratam do não determinismo (imprecisão, ambigüidade e/ou incerto) que poderão ser utilizadas?

O presente artigo busca apresentar uma pequena revisão do tema negociação e decisão, posteriormente focando na proposta principal, que é negociação e decisão em grupo.

\section{Considerações sobre Negociação e Decisão em Grupo}

\subsection{Negociação}

Um processo de negociação freqüentemente tem sua complexidade advinda do fato de ser este um processo dinâmico e mal estruturado com múltiplos participantes, opiniões divergentes, grupos de pressão etc. Além disso, muitas vezes os dados são imprecisos e os riscos não podem ser estimados adequadamente (Gomes, Gomes \& Teixeira, 2002).

Segundo Moreira (1998) a negociação pode ser definida como o processo no qual a decisão mútua (ou seja, o resultado da negociação obtido a partir da interação dos negociadores) é feita com a concordância das partes envolvidas. 
Na negociação existem fatores (interesses) políticos e/ou econômicos e não apenas técnicos que participam do processo, e estes fatores podem dificultar e até impedir a chegada do consenso (Gomes, Gomes \& Moreira, 1998).

As dificuldades da negociação em que existem múltiplos problemas envolvidos são, segundo (Matsatsinis \& Samaras, 2001):

$\Rightarrow$ Os problemas são de difícil modelagem, principalmente no que se refere aos impactos sociais;

$\Rightarrow$ É difícil satisfazer todas as necessidades e as restrições (simultaneamente);

$\Rightarrow$ Tem-se que maximizar objetivos conflitantes;

$\Rightarrow$ Envolvem critérios conflitantes.

$\mathrm{O}$ uso de metodologias diferentes gera ordenações diferentes (esta dificuldade obriga a comparação entre os resultados, o que por vezes não permite saber-se se uma alternativa domina ou não as outras como será apresentado na modelagem descrita em 4.0 Utilização de Metodologias do AMD para Negociação ou Decisão em Grupo).

Para Hipel \& Fraser (1984) temos as seguintes considerações sobre negociação:

- Negociação é uma seqüência de movimentos onde os adversários buscam um consenso (se possível favorável para as partes).

- Uma negociação pode ser acomodativa ou coerciva.

- Na negociação acomodativa os movimentos são cooperativos e envolvem ajustes em direção a um compromisso;

- Na negociação coerciva o movimento é agressivo e envolve um aumento em escala dos conflitos.

Conflito é uma condição de oposição, em que as metas de um lado (lado é definido como jogador, acordo definição existente em 3.3 Teoria da Utilidade e Teoria dos Jogos), bem como as atitudes deste mesmo lado, afetam o outro lado (normalmente a maximização das metas de um lado impede a maximização das metas do outro lado). As metas e as ambições de um lado interferem nas metas e ambições do outro lado.

- Coalizão é quando um grupo de jogadores escolhe agir de forma conjunta para benefício mútuo.

Para Matsatsinis \& Samaras (2001) o processo de negociação, entre centros e/ou atores de negociação (pessoas, países, sindicatos etc.) obedece a três princípios básicos:

- Definição prévia de uma estratégia - feita antes de iniciar a negociação;

- Utilização de táticas para negociação (busca da solução do problema) - executada durante a negociação; e

- Organização do procedimento de sobrevivência (estratégico e tático) - como proceder caso não sejam obtidos os resultados favoráveis.

Para Hipel \& Fraser (1984) uma estratégia de negociação só é possível quando um negociador possui "bastante tempo" para verificar "todas" as possibilidades. A tática de negociação é feita sem grande oportunidade de tempo de análise; é feita durante as negociações face-a-face e síncronas. 
Matsatsinis \& Samaras (2001) vislumbram duas grandes etapas durante a negociação:

- Etapa 1 - cada grupo coloca as suas propostas (soluções para o problema) para negociação. Este é o estágio de aprendizagem (verifica-se como cada grupo entende o problema, e quais são as preferências de cada grupo);

- Etapa 2 - surgimento de novas propostas fruto da aprendizagem, normalmente advindas da discussão ocorrida em cima das propostas de primeira etapa.

Na evolução da etapa 1 para 2 pode ocorrer:

$\Rightarrow$ identificação de novas metas;

$\Rightarrow$ substituição de metas;

$\Rightarrow$ introdução de novos critérios e/ou alternativas (neste artigo o termo alternativa tem o sentido de uma opção viável para solução de um problema);

$\Rightarrow$ eliminação de critérios e/ou alternativas;

$\Rightarrow$ mudança dos pesos (importância) atribuídos aos critérios.

Propõe-se que a negociação siga os seguintes passos:

- Cada grupo ou cada ator participante fornece as suas informações e suas preferências, criando o seu grupo de alternativas de solução do problema, informando os critérios de avaliação utilizados e os pesos (importância) atribuídos aos critérios (Leya-López \& Fernandez-González, 2003);

- Escolhe-se um grupo, ou pessoa (em discussões internacionais um coordenador ou secretário) que por meio de sua autoridade tenta (mas não impõe) buscar um conjunto de regras, e priorizar as informações dos membros. Gomes \& Gomes (1996) propõem o uso da Teoria dos Conjuntos Aproximativos para definição do conjunto de regras de negociação (em 3.1 Teoria dos Conjuntos Aproximativos - TCA este conceito será ampliado); e

- O grupo aceita (por consenso) a decisão final fruto da agregação das preferências do grupo.

Face ao anteriormente exposto conclui-se que a negociação se caracteriza por ser um processo de expansão e contração do conjunto de alternativas (soluções factíveis). A intensidade de preferência dos decisores/negociadores pode ser afetada pelo número de alternativas bem como pela contração e expansão das alternativas. E pode-se também supor que a distribuição marginal das preferências pelas alternativas não é uniforme. Um grupo "muito grande" de negociadores pode dificultar a interação dos mesmos e impossibilitar que se obtenham compromissos entre os negociadores (Gomes \& Gomes, 2005).

Depreende-se que a decisão e/ou negociação em grupo necessita:

- De informações das preferências dos atores, definidas, ou o mais definido possível;

- $\operatorname{Da}(s)$ definição(ões) do(s) problema(s) envolvido(s);

- De um grupo de alternativas a serem avaliadas;

- Dos critérios de decisão, pesos atribuídos a estes critérios, ou faixa de pesos.

Sugere-se que, para a negociação progredir, torna-se necessário verificar:

- Como um grupo aceita ou não as posições do outro grupo que são contrárias às suas posições - explorar as perspectivas de cada parte (Gomes, Gomes \& Teixeira, 2002); 
- Quais são os pontos de interesse comum, e quais são os pontos de divergência - iniciar a negociação pelo exame dos interesses, e não pelas posições divergentes; e buscar compreender os conflitos (Gomes \& Gomes, 1996);

- Se é possível encorajar os pontos de cooperação para reduzir a competição - gerar muitas opções e não descartar qualquer delas prematuramente (Gomes, Gomes \& Moreira, 1998);

- Se a introdução de novas regras e/ou grupos de negociadores impacta positivamente ou negativamente no processo de negociação (neste caso com a visão ganha-ganha); deve-se pensar como a introdução destas regras e participantes faz progredir a negociação melhorando a "nossa posição";

- Se é possível fazer coalizões; as coalizões podem ser formadas por interesses comuns, por exemplo, países subdesenvolvidos poderem quebrar patentes de remédios para fabricação nacional e assim melhorar o padrão de vida da população.

Bazerman (2004) identifica na negociação uma área denominada "Zona de Barganha", onde um negociador tem algum ponto de reserva abaixo ou acima, desta área, na qual o negociador preferiria o impasse ao acordo. Esta área é modelada tendo como base a "melhor alternativa a um acordo negociado" identificada pelo negociador em questão. Em torno desta "alternativa ótima" estão definidos os limites (acima e abaixo) que se pode "barganhar".

Bazerman (2004) sugere o seguinte procedimento para negociação:

- Juntar informações para criar valor na negociação;

- Cultivar confiança e compartilhar informações de forma estratégica;

- Fazer múltiplas ofertas simultaneamente; e

- Buscar por acordos pós-acordos.

\subsubsection{Negociação internacional}

Uma negociação internacional pode ocorrer com o propósito de buscar-se um acordo e/ou que ao final gere, por exemplo, uma convenção aceita pelos países participantes. Entretanto, neste caso em particular, o acordado não necessariamente acarreta que esta convenção entrará em vigor, pois:

a) Normalmente para homologação de uma convenção existem negociações ditas "técnicas" que antecedem a uma reunião diplomática (em que os embaixadores homologam a convenção). Existe a necessidade de um número predeterminado, normalmente de dois terços dos presentes, ou dois terços dos países filiados à organização, aprovarem o texto para a homologação diplomática. A alteração do quorum de países, seja pela ausência de um país, ou, a presença de outro na homologação diplomática, pode alterar este valor de dois terços, que anteriormente tinham aprovado a convenção;

b) Entre uma reunião e outra, um país pode mudar sua posição;

c) Após a homologação diplomática existe a assinatura, porém, por vezes, a assinatura só é possível após a aprovação do legislativo do país, no caso do Brasil, o Senado Federal, que por algum motivo pode não aceitar e/ou atrasar a autorização (e a conseqüente homologação), e assim sendo, o documento pode ter de esperar alguns anos para ter as assinaturas mínimas para entrar em vigor. Caso este período se estenda, algum país pode pedir revisão da convenção, motivado "por mudanças no cenário mundial, ou evoluções tecnológicas" ou outro motivo, e assim reiniciar o processo. 
Por vezes vários processos de negociação ocorrem paralelos, em fóruns diferentes, até em países diferentes, e a mudança de posição de um negociador, e/ou a flexibilidade deste negociador mudar a sua posição ou chegar a um acordo pode ser fruto de uma atitude semelhante do outro negociador em um outro processo de negociação; por exemplo, a negociação do País A com o País B para a compra por parte de A de aviões de guerra em que o País B é um dos cinco possíveis fornecedores, pode ocorrer simultaneamente com a concorrência internacional de uma grande empresa de aviação comercial do País B, em que o País A dispõe de uma empresa que fabrica aviões comerciais, e é um dos possíveis fornecedores. Logo a vitória de B na concorrência de A pode ser negociada com a vitória de A na concorrência de B.

Salienta-se que uma delegação que vai para uma negociação pode ter internamente pontos divergentes, e conflitantes. Exemplifica-se o caso de uma negociação internacional para normas portuárias, na qual um país que envia em sua delegação um Membro do Ministério do Meio Ambiente e um Membro do Ministério do Transporte. Estes podem ter opiniões diferentes sobre os gastos com proteção ambiental no porto. Face ao exemplo anteriormente exposto, a própria posição de uma delegação já é fruto de uma negociação.

Em 3.1 Teoria dos Conjuntos Aproximativos - TCA será proposta uma modelagem onde o fator denominado "peso do negociador" tem uma aplicação em negociação internacional.

\subsection{Decisão em grupo}

Assumindo que decisões em grupo de naturezas empresariais, governamentais, trabalhistas, bem como, militares, são tomadas, normalmente, em ambientes complexos, e, por conseguinte, os estudos científicos da análise de conflitos e da facilitação da chegada ao consenso são altamente relevantes do ponto de vista prático (Gomes, 1991).

Para Matsatsinis \& Samaras (2001) o processo da decisão em grupo pode:

$\Rightarrow$ Envolver uma diferenciação espacial (local ou remoto), pois pode ter interação face a face ou não;

$\Rightarrow$ Ser temporal, pois podem ocorrer encontros ou apenas telefonemas, ou pode ocorrer troca de e-mails acarretando que a troca de informações pode ser síncrona ou assíncrona;

$\Rightarrow$ Ser cooperativo ou não; e

$\Rightarrow$ Ser democrático, hierárquico ou conflitante.

A análise das alternativas por um grupo ou grupos de atores da decisão, em um processo decisório, pode vislumbrar que existe:

(a) a coletiva preferência por uma ou mais alternativas;

(b) a coletiva não preferência por uma ou mais alternativas;

(c) a coletiva indiferença por uma alternativa ou um grupo de alternativas;

(d) conflito de forma coletiva;

(e) a coletiva preferência fraca por uma alternativa ou mais alternativas;

(f) a coletiva não classificação das alternativas (pode ser causada pela impossibilidade técnica e por vezes política de se efetuar a classificação da alternativa); ou

(g) a coletiva repulsa pelas alternativas.

A grande dificuldade do processo decisório está em lidar com a necessidade de satisfazer restrições e metas, e a existência de objetivos e critérios conflitantes, sendo estes dois 
últimos o principal campo de pesquisa do Apoio Multicritério à Decisão (AMD) (Chen \& Lin, 2003).

Takeda (2001) expõe que os problemas de decisão complexa envolvem critérios conflituosos, com classificações imprecisas das alternativas nos critérios, gerando incertezas e indeterminações, e identifica três fenômenos:

- Imprecisões advindas da difículdade de determinar os dados (Mármol, Puerto \& Fernández, 2002);

- Indeterminações advindas do uso de forma arbitrária de métodos de avaliação das informações (escolha indevida dos métodos face a quantidade de métodos existentes); e

- Incerteza advinda das variações dos dados ao longo do tempo.

Gomes, Gomes \& Teixeira (2002) propõem que o AMD ao tratar dos fenômenos descritos por Takeda (2001) utilize a Teoria dos Conjuntos Nebulosos e/ou Inferência Bayesiana para tratar as imprecisões; já a incerteza deveria ser tratada pela probabilidade; e as indiscernibilidades sejam objeto de estudo da Teoria dos Conjuntos Aproximativos (TCA).

Salienta-se que a comparação das sugestões advindas pelo uso de métodos diferentes poderá auxiliar a identificação de erros no processo decisório e/ou identificar o(s) método(s) que melhor se aplica $(\mathrm{m})$ ao processo decisório. $\mathrm{O}(\mathrm{s})$ decisor(es) deve(m) ter sempre em mente as limitações dos métodos de decisão, e que a própria escolha do método influencia o processo de decisão.

Observação: a decisão em grupo e a negociação, freqüentemente podem usar as mesmas ferramentas para apoiar o processo, porém isto não caracteriza que sejam sinônimos. Um exemplo diferenciador clássico é que a decisão em grupo permite o uso da votação para sair de um impasse, fato este que não é aceito na negociação. A negociação busca um consenso, a decisão em grupo busca uma maioria. O nível de conflitos será um dos fatores que permitirá avaliar se será usado um sistema de apoio à decisão em grupo ou um sistema de apoio à decisão negociada. Outro fator é se a decisão pode ser obtida por maioria, que pode ser simples no caso de $50 \%$ mais um, ou maioria de dois terços, etc, ou se requer consenso.

\section{Modelagem Analítica}

\subsection{Teoria dos Conjuntos Aproximativos - TCA}

Ao longo de um processo típico de negociação, alternativas e critérios (quantidade) evoluem, bem como também evolue (altera) a importância atribuída aos critérios, e por conseqüência a importância de uma alternativa. Captar tal evolução de uma forma on-line acarreta saber-se resolver as múltiplas imprecisões eventualmente causadas por hesitações ou dúvidas, associadas aos cenários que vão se desvendando durante o processo (Moreira \& Gomes, 1995).

Em um processo de negociação existem em paralelo as alternativas consensualmente consideradas claramente factíveis ou, de modo exclusivo, claramente consideradas não factíveis. Há três categorias de ações que devem ainda ser contempladas, para qualquer negociador:

(I) Alternativas inicialmente consideradas factíveis e posteriormente consideradas não factíveis;

(II) Alternativas inicialmente consideradas não factíveis e posteriormente consideradas factíveis; 
(III) Alternativas que surgem durante o processo de negociação, seja pela evolução do processo, seja pela evolução do meio ambiente ou pela entrada de novos atores no processo. Esses novos atores podem ser centros de decisão (por exemplo: países que aderem a uma negociação, sindicatos que decidem participar de um processo já iniciado, ou a própria troca do representante de uma delegação). Salienta-se, também para exemplificar, que a troca de governo em um país pode causar a mudança da posição deste país em uma negociação.

Esses três conjuntos de alternativas contêm indiscernibilidades. Para tal sugere-se uma abordagem pela TCA (Gomes \& Gomes, 1996; Zaras, 2004). Podem ocorrer divergências entre negociadores, o que nos leva às seguintes principais indiscernibilidades no processo:

a) Conjuntos de alternativas podem ser indiscerníveis para um particular grupo de negociadores;

b) Conjunto de alternativas pode ser indiscernível para todos os negociadores;

c) Conjunto de alternativas torna-se indiscernível, pois seus graus de factibilidade evoluem ao longo do processo;

d) As importâncias relativas atribuídas aos critérios de negociação em si podem ser indiscerníveis, seja:

i) Por dificuldade de atribuir peso (importância relativa) a um critério ou grupo de critérios; e/ou

ii) Pela importância relativa dos critérios evoluírem ao longo do processo de negociação.

A TCA foi proposta em 1982 por Zadislaw Pawlak (Pawlak, 1982). Como teoria científica, trata da questão da granulosidade da representação de um problema. Essa granulosidade causa indiscernibilidade, que, por sua vez, impede a revelação de estruturas ou padrões de classificação, com base em dados que refletem uma experiência. A TCA, em essência, constitui-se em um instrumental para transformar um conjunto de dados em conhecimento (Pawlak, 1996). Por esse motivo, é uma análise para representação de conhecimento. A TCA é caracterizada por um conjunto de elementos que não pode ser precisamente definido no que concerne a seus atributos; a relação de indiscernibilidade constitui a base matemática da TCA. A TCA é a primeira metodologia não estatística para análises de dados (Gomes, Gomes \& Teixeira, 2002). Essa metodologia tem como vantagem, em relação à probabilidade em estatística, o fato de não necessitar de um banco preliminar de dados (Slowinski, Salvatore \& Benedetto, 1995 e 1996).

A TCA baseia-se principalmente na idéia de indiscernibilidade entre dois objetos. Essa relação de indiscernibilidade pode ser entendida como binária, à medida que dois objetos possuem a mesma descrição, porém de atributos diferentes.

A TCA pode ser utilizada na modelagem analítica embutida em um Sistema nas seguintes etapas de tal modelagem:

(a) Definição de uma função $\mathrm{F}(\mathrm{x}, \mathrm{y})$, denominada "Função Negociação", no caso em que há somente dois agentes de negociação; no caso mais geral, essa função poderá ter $n$ argumentos (ou negociadores), sendo $\mathrm{n}$ um número inteiro, positivo e maior ou igual a dois. A Função de Negociação tem como propósito identificar os negociadores no caso $\mathrm{x}$ e $\mathrm{y}$. A $\mathrm{F}(\mathrm{x}, \mathrm{y})$ assumirá valor ZERO quando não houver propensão à negociação, e um valor maior que ZERO quando existir a propensão à busca de um consenso. Os conjuntos definidos, a seguir, em (b), (c) e (d) possibilitarão ou não o desenvolvimento da negociação; 
(b) Construção de $\mathrm{C}=$ conjunto de critérios; esse conjunto será a união dos critérios $\mathrm{cx}$, próprios do negociador $\mathrm{x}$, e cy, próprios do negociador $\mathrm{y}$. A função $\mathrm{F}$ só é definida se $\mathrm{C} \neq \varnothing$;

(c) Geração de $\mathrm{W}=$ conjunto dos pesos dos critérios cx e cy, sendo assim, $\mathrm{W}=\{\mathrm{wx}$, wy);

(d) Identificação do peso do negociador (ou delegação) $\{\mathrm{X}, \mathrm{Y}\}$ ou o peso do grupo que o negociador representa.

O fator denominado "peso do negociador" tem grande relevância em fóruns internacionais. O peso do negociador (representação do país) é, basicamente, produto dos seguintes fatores:

a) Capacidade da delegação se expressar na língua da negociação, pois nem sempre existe tradução simultânea;

b) Credibilidade do país, que é fruto do somatório do seu poder econômico, diplomático, político e militar - por vezes uma forte preponderância em um destes poderes (especialmente o militar ou o econômico) pode fazer uma delegação ignorar um acordo ou até as normas de condução de uma negociação; o exemplo que se vê no mundo, atual, em que a única superpotência econômico/militar tem um "peso" que lhe permite ignorar decisões da ONU e/ou impor-se frente à ONU. Situações como essa podem, a médio prazo, criar um descrédito nos fóruns internacionais que podem levar inclusive à sua dissolução, como aconteceu com a Liga das Nações em 1946, uma vez que esta organização não conseguiu evitar as agressões que antecederam e geraram a Segunda Guerra Mundial. A oposição a um país com peso do negociador extremamente alto está em uma opinião pública internacional que possa desmotivá-lo de uma atitude hegemônica, demonstrando ojeriza a este comportamento e podendo culminar com boicotes a seus produtos, que gerem um impacto econômico que force a opinião pública do país a fazer o seu governo rever suas posições;

c) Credibilidade dos membros da delegação, fruto dos conhecimentos específicos sobre o assunto que está sendo negociado, por exemplo, quando se discute normas de navegação, uma delegação com Diplomatas, Engenheiros Navais, Oficiais de Marinha Mercante, Oficiais de Marinha de Guerra etc, tem mais força que uma delegação composta unicamente por Diplomatas. A apresentação de artigos e/ou documentação técnica baseada em pesquisas feitas pelos membros da delegação, e/ou retirada de periódicos ou livros, é uma forma de aumentar a credibilidade das propostas apresentadas. A contestação de uma proposta contrária aos interesses de um grupo pode ser facilitada apresentando-se documentação que conteste a posição do outro grupo, ou pelo menos, apresente uma "outra visão", que nos seja favorável, demonstrando que a "comunidade científica" está dividida, e a posição contrária aos nossos interesses não é a única;

d) Quantidade de membros na delegação, pois freqüentemente coexistem em uma negociação fóruns paralelos e torna-se necessário fazer-se presente em todos, e a existência de uma delegação com múltiplos conhecimentos, como descrito no exemplo de c) facilita a delegação emitir opiniões ou discutir um tema sobre várias óticas;

e) Quantidade de votos que a delegação possui; por exemplo, quando a União Européia "fecha" questão em uma negociação, sempre haverá tantos votos na questão quanto os membros da União Européia (países), ou uma situação em que a Rainha do Reino Unido é Chefe de Estado de mais de um país é possível solicitar apoio destes países, em que ela é Chefe de Estado, a uma causa de interesse do Reino Unido.

Ao iniciar-se um processo de negociação poderá ocorrer que os negociadores $\mathrm{x} e \mathrm{y}$ identifiquem um mesmo conjunto de critérios, $\mathrm{cx}, \mathrm{cy} \in \mathrm{C}$, para negociação, porém atribuam pesos, wx, wy $\in \mathrm{W}$, (importância) diferentes. 
Neste caso cx poderá ser igual a cy, porém $w x \neq w y$; ou poderá ocorrer que os negociadores $\mathrm{x}$ e $\mathrm{y}$ identifiquem critérios diferentes, e neste caso teremos $\mathrm{cx} \neq \mathrm{cy}$. Neste último caso, um decisor poderá convidar o outro a atribuir pesos aos critérios, após a definição do conjunto de critérios a ser utilizado.

A situação ideal será a que os decisores atribuam os mesmos pesos ao conjunto de critérios identificados.

Identificação de uma função $\mathrm{L}(\mathrm{x}, \mathrm{y})$ ou, o que é equivalente, $\mathrm{L}(\mathrm{F}(\mathrm{x}, \mathrm{y}), \mathrm{A})$, sendo A o conjunto de objetos factíveis da negociação (ou ações potenciais factíveis ou alternativas de negociação); uma vez que se pretende maximizar $\mathrm{L}(\mathrm{F}(\mathrm{x}, \mathrm{y}), \mathrm{A})$, a TCA, através do índice de indiscernibilidade, possibilitará o desenvolvimento de algoritmos maximizadores.

O Conjunto A tem na sua definição os seguintes pontos a considerar (Halpern \& Chu, 2001):

- Conjunto $\mathrm{S}$ no qual si $\in \mathrm{S}$, si representa cada cenário, ou possível cenário futuro, que o negociador vislumbra; no qual cada si possui associada a esta uma probabilidade (pri) atribuída pelo negociador;

- Conjunto $\mathrm{O}$ no qual oj $\in \mathrm{O}$, oj representa as observações do negociador.

A expressão da $\mathrm{F}(\mathrm{cx}, \mathrm{cy}$, wx, wy) assumirá valores de 0 a 1 , uma vez normalizada - neste caso 0 significa conflito total, ao passo que 1 significa consenso total. Com isso, associa-se a $\mathrm{F}(\mathrm{x}, \mathrm{y})$ ao conceito de índice de indiscernibilidade da TCA. O peso do negociador influenciará sobremaneira na atribuição dos valores 0 a 1 em $\mathrm{F}(\mathrm{x}, \mathrm{y})$.

\subsubsection{Exemplo numérico}

Passa-se agora a mostrar como as indiscernibilidades existentes em um processo de negociação podem ser resolvidas pela TCA. Como exemplo ilustrativo, considera-se o sistema de informação (Tabela I), disponível em um dado momento do processo de negociação, abaixo representado. Em tal sistema, o atributo de decisão pode assumir alternativamente os valores F (factível) e NF (não factível), tendo-se seis ações (a1, a2, ... , a6) que são os objetos de negociação, seis atributos de condição e os critérios de negociação $(\mathrm{c} 1, \mathrm{c} 2, \ldots, \mathrm{c} 6)$.

Tabela I - Alternativas classificadas nos critérios.

\begin{tabular}{|c|c|c|c|c|c|c|c|}
\cline { 2 - 8 } \multicolumn{1}{c|}{} & $\mathrm{c} 1$ & $\mathrm{c} 2$ & $\mathrm{c} 3$ & $\mathrm{c} 4$ & $\mathrm{c} 5$ & $\mathrm{c} 6$ & Atributo \\
\hline $\mathrm{a} 1$ & 5 & 3 & 5 & 3 & 6 & 4 & $\mathrm{~F}$ \\
\hline $\mathrm{a} 2$ & 4 & 5 & 5 & 1 & 1 & 5 & $\mathrm{~F}$ \\
\hline $\mathrm{a} 3$ & 3 & 5 & 4 & 3 & 2 & 5 & $\mathrm{NF}$ \\
\hline $\mathrm{a} 4$ & 3 & 6 & 3 & 2 & 1 & 4 & $\mathrm{NF}$ \\
\hline $\mathrm{a} 5$ & 5 & 4 & 4 & 6 & 5 & 3 & $\mathrm{~F}$ \\
\hline $\mathrm{a} 5$ & 5 & 4 & 4 & 6 & 5 & 3 & $\mathrm{NF}$ \\
\hline $\mathrm{a} 6$ & 2 & 3 & 6 & 3 & 4 & 4 & $\mathrm{~F}$ \\
\hline $\mathrm{a} 6$ & 2 & 3 & 6 & 3 & 4 & 4 & $\mathrm{NF}$ \\
\hline
\end{tabular}


Observação: A aproximação inferior é uma região em que positivamente sabemos que os elementos pertencem ao conjunto em análise. A aproximação superior corresponde o máximo de objetos que podem pertencer ao conjunto em análise (Pawlak, 1982 e 1996; Slowinski, Salvatore \& Benedetto, 1996 e 1997; Zaras, 2004).

Pela aproximação inferior tem-se PYF [a1, a2], PYNF [a3, a4]. Pela aproximação superior por sua vez, tem-se PYF [a1, a2, a5, a6], PYNF [a3, a4, a5, a6]. Vê-se, assim, que tanto F como NF têm $50 \%$ de indiscernibilidade.

Por intermédio de a1, a2, a3 e a4 obtêm-se as seguintes regras:

- Regra 1 - se c1 $\geq 4$ e c3 $\geq 5$ a alternativa é considerada F;

- Regra $2-$ se $\mathrm{c} 1 \leq 3$ é considerada NF.

Observação: poder-se-ia fazer uma simplificação, neste exemplo, colocando apenas a Regra: c1 $\geq 4$ e c $3 \geq 5$ a alternativa é considerada $F$, caso contrário NF, mas para melhor entendimento da Metodologia manteve-se as duas Regras.

As regras são obtidas pela cognição do negociador/decisor buscando identificar a "melhor" forma de reduzir as indiscernibilidades. O negociador/decisor deve identificar padrões.

Aplicando-se as regras acima às alternativas a5 e a6 verifica-se que a5 atende na Regra 1 em c1, mas não atende à Regra 1 para c3; por conseguinte, é considerada NF. Por outro lado, a6 atende à Regra 1 para c3, mas não atende na Regra 1 em c1, e a6 enquadra-se na Regra 2; logo a6 também é considerada NF.

Essa análise, portanto, indica que a indiscernibilidade é removível e que os critérios c2, c4, c5 e c6 (Tabela II) não são relevantes para a negociação. Uma análise idêntica a essa pode ser efetuada para outras situações usualmente encontradas em processos de negociação. $\mathrm{O}$ novo sistema de informação (Tabela II) será:

Tabela II - Alternativas classificadas nos critérios relevantes.

\begin{tabular}{|c|c|c|c|}
\cline { 2 - 4 } \multicolumn{1}{c|}{} & $\mathrm{c} 1$ & $\mathrm{c} 3$ & Atributo \\
\hline $\mathrm{a} 1$ & 5 & 5 & $\mathrm{~F}$ \\
\hline $\mathrm{a} 2$ & 4 & 5 & $\mathrm{~F}$ \\
\hline $\mathrm{a} 3$ & 3 & 4 & $\mathrm{NF}$ \\
\hline $\mathrm{a} 4$ & 3 & 3 & $\mathrm{NF}$ \\
\hline $\mathrm{a} 5$ & 5 & 4 & $\mathrm{NF}$ \\
\hline $\mathrm{a} 6$ & 2 & 6 & $\mathrm{NF}$ \\
\hline
\end{tabular}

Assim, chega-se à regra única: $\mathrm{se} \mathrm{c} 1 \geq 4 \mathrm{e} \mathrm{c} 3 \geq 5$ a alternativa é considerada $\mathrm{F}$, caso contrário é considerada NF.

Salienta-se que neste exemplo o peso do negociador, descrito anteriormente já influenciou a atribuição de F ou NF.

A TCA permitiu verificar que, neste exemplo, somente dois critérios (c1 e c3) foram considerados relevantes para classificar as alternativas como $\mathrm{F}$ ou NF. 


\subsection{Modelo do Hiperjogo (tradução de Hypergame)}

Modelo do Hiperjogo é aplicado quando (Hipel \& Fraser, 1984):

- Existe um falso entendimento das preferências entre os jogadores; e/ou

- Tem-se uma compreensão incorreta das posições entre os jogadores.

\section{Modelo do Hiperjogo:}

Tabela III.

\begin{tabular}{|c|c|c|c|c|}
\hline \multirow{2}{*}{ Percepção do jogador } & \multicolumn{4}{|c|}{ Percepção do jogo por cada jogador } \\
\cline { 2 - 5 } & 1 & 2 & $\ldots$ & $\mathrm{n}$ \\
\hline 1 & $\mathrm{~V}_{11}$ & $\mathrm{~V}_{12}$ & $\ldots$ & $\mathrm{V}_{1 \mathrm{n}}$ \\
\hline 2 & $\mathrm{~V}_{21}$ & $\mathrm{~V}_{22}$ & $\ldots$ & $\mathrm{V}_{2 \mathrm{n}}$ \\
\hline$\ldots$ & $\ldots$ & $\ldots$ & $\ldots$ & $\ldots$ \\
\hline $\mathrm{N}$ & $\mathrm{V}_{\mathrm{n} 1}$ & $\mathrm{~V}_{\mathrm{n} 2}$ & $\ldots$ & $\mathrm{V}_{\mathrm{nn}}$ \\
\hline & $\mathrm{G}_{1}$ & $\mathrm{G}_{2}$ & $\ldots$ & $\mathrm{G}_{\mathrm{n}}$ \\
\hline
\end{tabular}

$\mathrm{G}_{\mathrm{i}}=$ percepção total do jogo pelo jogador $\mathrm{i}$;

$\mathrm{V}_{\mathrm{i}}=$ preferência de cada jogador $\mathrm{i}$;

$\mathrm{V}_{\mathrm{iq}}=$ preferência do vetor $\mathrm{V}$ pelo jogador $\mathrm{i}$ imaginada pelo jogador $\mathrm{q}$;

$\mathrm{G}=\left\{\mathrm{V}_{1}, \mathrm{~V}_{2}, \ldots, \mathrm{V}_{\mathrm{i}}\right)$, para $\mathrm{i}=1$ a $\mathrm{n}$;

$\mathrm{G}_{\mathrm{q}}=\left\{\mathrm{V}_{1 \mathrm{q}}, \mathrm{V}_{2 \mathrm{q}}, \ldots, \mathrm{V}_{\mathrm{nq}}\right\}$, para os $\mathrm{n}$ jogadores na visão de $\mathrm{q}$ (Tabela III);

Tabela IV.

\begin{tabular}{|c|c|c|c|c|}
\hline \multirow{2}{*}{ Percepção do jogador } & \multicolumn{5}{|c|}{ Percepção do Hiperjogo por cada jogador } \\
\cline { 2 - 5 } & 1 & 2 & $\ldots$ & $\mathrm{n}$ \\
\hline 1 & $\mathrm{G}_{11}$ & $\mathrm{G}_{12}$ & $\ldots$ & $\mathrm{G}_{1 \mathrm{n}}$ \\
\hline 2 & $\mathrm{G}_{21}$ & $\mathrm{G}_{22}$ & $\ldots$ & $\mathrm{G}_{2 \mathrm{n}}$ \\
\hline$\ldots$ & $\ldots$ & $\ldots$ & $\ldots$ & $\ldots$ \\
\hline $\mathrm{N}$ & $\mathrm{G}_{\mathrm{n} 1}$ & $\mathrm{G}_{\mathrm{n} 2}$ & $\ldots$ & $\mathrm{G}_{\mathrm{nn}}$ \\
\hline & $\mathrm{H}_{1}$ & $\mathrm{H}_{2}$ & $\ldots$ & $\mathrm{H}_{\mathrm{n}}$ \\
\hline
\end{tabular}

$\mathrm{H}=$ somatório das percepções dos jogadores;

$\mathrm{H}=\left\{\mathrm{G}_{1}, \mathrm{G}_{2}, \ldots, \mathrm{G}_{\mathrm{n}}\right\}$;

$\mathrm{H}_{\mathrm{q}}=$ percepção das preferências dos outros jogadores por $\mathrm{q}, \mathrm{G}_{\mathrm{iq}}$, para $\mathrm{i}=1, \ldots, \mathrm{n}$;

$\mathrm{H}_{\mathrm{q}}=\left\{\mathrm{G}_{1 \mathrm{q}}, \mathrm{G}_{2 \mathrm{q}}, \ldots, \mathrm{G}_{\mathrm{nq}}\right\}$;

$\mathrm{H}^{2}=$ percepção dos jogadores do jogo como um todo $=\left\{\mathrm{H}_{1}, \mathrm{H}_{2}, \ldots, \mathrm{H}_{\mathrm{n}}\right\}$ (Tabela IV).

\subsection{Teoria da Utilidade e Teoria dos Jogos}

A noção de utilidade foi descrita em 1738 num artigo por Daniel Benoulli como unidade para medir preferências (associou noções tais como: quanto gostamos mais de um bem do que de outro; quanto mais temos de algo, menos estamos dispostos a pagar mais). Depois Jeremy Bentham, em obra publicada em 1789, trata dessa noção. Ele destacou que a humanidade 
estaria sob o governo de dois senhores: a dor e o prazer. Associou à noção de utilidade "propriedade em qualquer objeto, pela qual ele tende a produzir benefício, vantagem, prazer, bem ou felicidade" (Gomes, Gomes \& Teixeira, 2002).

Uma vez maximizada a Função Negociação, descrita na sessão 3.1 Teoria dos Conjuntos Aproximativos - TCA, o decisor poderá utilizar-se da Teoria da Utilidade Multiatributo para construção de uma nova função que traduzirá a "agregação de valor" de cada alternativa. Esta nova função trará dois benefícios seguintes:

a) Permitirá verificar a sensibilidade do resultado obtido através da TCA; e

b) Viabilizará a priorização das alternativas.

A Teoria dos Jogos é uma teoria que trata os aspectos gerais de situações competitivas, dando ênfase ao processo de tomada de decisão dos adversários (Liberman \& Hillier, 1988). A Teoria dos Jogos desenvolve critérios racionais para a seleção de uma estratégia.

Segundo Osborne \& Rubinstein (1994) a Teoria dos Jogos é um conjunto de ferramentas criadas para auxiliar o entendimento dos fenômenos observados quando os decisores, no caso jogadores, interagem.

A Teoria dos Jogos faz uso da modelagem matemática para expressar formalmente as idéias compreendidas e inseridas no modelo.

A Teoria dos Jogos está inserida na Pesquisa Operacional e na Economia e pretende descrever e prever o comportamento decisório e/ou econômico utilizando modelos matemáticos visando à análise e coordenação de situações de conflito (Liberman \& Hillier, 1988). O decisor disputa um jogo com um oponente não passivo, pois os jogadores tentam ativamente promover as respectivas prosperidades, em oposição ao outro. Um jogo pode ser definido como uma interação entre agentes regulados por um conjunto de regras que especificam os movimentos possíveis de cada participante e por um conjunto de resultados para cada possível combinação de movimentos (Von Neuman \& Morgenstern, 1953). Whinston \& Mas-Colell (1995) definem jogo como "uma representação formal de uma situação em que os indivíduos (jogadores) interagem por meio de um conjunto de estratégias de forma interdependente". O jogo é uma situação na qual um ou mais jogadores confrontam-se em busca de certos objetivos conflitantes.

Um jogo é dito de informação completa quando os jogadores têm níveis de informação no jogo equivalentes, e as regras que norteiam cada ação no jogo são de conhecimento comum para cada participante.

Ao estudar-se a negociação sob o enfoque da Teoria dos Jogos, observa-se que o objetivo de maximização é limitado pela capacidade do ser humano de discernir o mundo, neste compreendidos os critérios e seus diferentes graus de importância, o que sugere haver um limite para a racionalidade.

A Teoria dos Jogos descreve a seguinte situação estratégica:

a) Jogadores - pessoas, instituições, centro de decisões, países etc, envolvidos. Suposto que sejam racionais agindo na forma de maximizar as suas utilidades (Souza, 2002). Salientase que uma decisão pode ser racional pelos valores de um jogador e não ser racional pelos valores de outro;

b) Regras - como jogar, como se comportar, o que o "outro" pode fazer, o que o "outro" sabe; 
c) Conjunto de ações - são as diversas seqüências de ações que podem ser adotadas ao longo do tempo pelos jogadores envolvidos (Souza, 2002). Uma jogada ou movimento é o modo como progride o jogo de uma fase para outra, a partir da posição inicial até o último movimento;

d) Resultados - para cada conjunto de ações dos jogadores, tem-se o "resultado do jogo";

e) "Payoffs" ou retornos - quais são as preferências dos jogadores, e qual é a utilidade que cada jogador obtém de cada resultado possível;

f) Estratégia - uma estratégia é a lista de opções ótimas para cada jogador, em qualquer momento do jogo.

O ponto de equilíbrio em que nenhum jogador tem incentivo para trocar a sua estratégia, também definido como o ponto em que cada jogador está fazendo o melhor que pode para si, é o Equilíbrio de Nash. O Equilíbrio de Nash se traduz em um jogador buscar o melhor resultado dentro da estratégia escolhida, e adotada, pelo jogador rival (Whinston \& MasColell, 1995). A ausência de equilíbrio tornará necessário expandir o conjunto de ações (alternativas que surgem durante o processo, como explanado anteriormente).

Para Bazerman (2004) a Teoria dos Jogos, na visão dos economistas, provê o conselho prescritivo aos negociadores, na forma mais precisa disponível, salientando ser esta a vantagem da Teoria dos Jogos. Entretanto tem como desvantagem ter de se basear na capacidade de descrever completamente todas as opções e resultados associados a cada possível combinação do conjunto de ações, e requer que os jogadores permaneçam consistentes e de forma racional.

Para Souza (2002) o termo negociação é tratado como Jogos Cooperativos, e os Jogos NãoCooperativos, que ao contrário do anterior existe o conflito de interesses é tratado pela Teoria dos Jogos. Os Jogos Cooperativos ocorrem quando existem interesses complementares. Em qualquer processo com dois ou mais jogadores fica muito difícil ocorrer isoladamente um Jogo Cooperativo e um Não Cooperativo. O que ocorre são oscilações de um para o outro. A flexibilidade de um jogador em um Jogo Não-Cooperativo poderá ser função da atitude do outro jogador em um Jogo Não-Cooperativo que ambos tenham participado anteriormente.

\subsubsection{Exemplo numérico}

A utilidade dos jogos pode ser calculada utilizando o descrito por de von Newman \& Morgenstern (1953) e pela Teoria da Utilidade Multiatributo desenvolvendo-se a função $\mu(\mathrm{Gi})$ (Souza, 2002):

$$
\mu(\mathrm{Gi})=\mu[\lambda \mathrm{i} \rho \mathrm{j}+(1-\lambda \mathrm{i}) \rho \mathrm{k}]=\lambda \mathrm{i} \mu(\rho \mathrm{j})+(1-\lambda \mathrm{i}) \mu(\rho \mathrm{k}) .
$$

$\rho \mathrm{j}, \mathrm{j}=1,2, \ldots, \mathrm{n}$. $\rho \mathrm{k}, \mathrm{k}=1,2, \ldots, \mathrm{n}$. No qual $\rho \mathrm{j}$ são as perguntas ou comparações que cobrem todo o processo; nesta situação associamos uma probabilidade $\lambda i$ de obtenção de um resultado $\rho j$ ou uma probabilidade $(1-\lambda \mathrm{i})$ de se obter um resultado $\rho \mathrm{k}$.

Torna-se intuitivo que um aumento de perguntas, ou comparações, pode gerar um conseqüente aumento de inconsistências (Souza, 2002). Uma possibilidade de reduzir estas inconsistências, pela retirada de perguntas que não agreguem utilidade é o uso da TCA, já mostrado em 3.1 Teoria dos Conjuntos Aproximativos - TCA, e aplicado de forma conjunta com a Teoria da Utilidade no exemplo que se segue: 
Tabela V - Perguntas e a utilidade correspondente.

\begin{tabular}{|c|c|c|c|}
\cline { 2 - 4 } \multicolumn{1}{c|}{} & $\mu(\lambda \mathrm{i} \rho \mathrm{j})$ & $\mu((1-\lambda \mathrm{i}) \rho \mathrm{k})$ & Atributo \\
\hline$\rho 1$ & 5 & 5 & $\mathrm{~F}$ \\
\hline$\rho 2$ & 4 & 5 & $\mathrm{~F}$ \\
\hline$\rho 3$ & 3 & 4 & $\mathrm{NF}$ \\
\hline$\rho 4$ & 3 & 4 & $\mathrm{NF}$ \\
\hline$\rho 5$ & 5 & 4,1 & $\mathrm{~F}$ \\
\hline$\rho 6$ & 5 & 4,1 & $\mathrm{NF}$ \\
\hline$\rho 7$ & 2,5 & 6 & $\mathrm{~F}$ \\
\hline$\rho 8$ & 2,5 & 6 & $\mathrm{NF}$ \\
\hline
\end{tabular}

Observação: a quantificação utilizada, na Tabela $\mathrm{V}$, advém de um valor subjetivo (expressando a atratividade) identificado pelo decisor/negociador apresentado na forma numérica utilizando o conceito da escala de intervalos. Para melhor explanação do conceito de escalas sugere-se consultar Anexo B de Gomes, Gomes \& Teixeira (2002).

Pela aproximação inferior tem-se $\operatorname{PYF}[\rho 1, \rho 2]$, PYNF[ $[\rho, \rho 4]$. Pela aproximação superior, por sua vez, tem-se PYF $[\rho 1, \rho 2, \rho 5, \rho 6, \rho 7, \rho 8]$, PYNF[ $\rho 3, \rho 4, \rho 5, \rho 6, \rho 7, \rho 8]$. Vê-se, assim, que tanto F como NF têm $33,33 \%$ de indiscernibilidade. Observando que $\rho 5$ é igual a $\rho 6$, e $\rho 7$ é igual a $\rho 8$.

Obtém-se as regras iniciais:

- Regra $1-$ se $\mu(\lambda$ i $\rho j) \geq 4$ e $\mu((1-\lambda i) \rho k) \geq 5$ a alternativa é considerada $F$;

- Regra $2-$ se $\mu(\lambda \mathrm{i} \rho j) \leq 3$ ou $\mu((1-\lambda \mathrm{i}) \rho \mathrm{k}) \leq 4,1$ é considerada NF.

A Regra 2 pode ser eliminada frente a Regra 1, e à Regra 1, ficando apenas: se $\mu(\lambda \mathrm{i} \rho \mathrm{j}) \geq 4 \mathrm{e}$ $\mu((1-\lambda \mathrm{i}) \rho \mathrm{k}) \geq 5$ a alternativa é considerada $\mathrm{F}$, caso contrário NF. Nesta situação não foi possível reduzir os critérios de decisão. O novo sistema de informação (Tabela VI) será:

Tabela VI - Utilidades relevantes definindo a Factibilidade.

\begin{tabular}{|c|c|c|c|}
\cline { 2 - 4 } \multicolumn{1}{c|}{} & $\mu(\lambda \mathrm{i} \rho \mathrm{j})$ & $\mu((1-\lambda \mathrm{i}) \rho \mathrm{k})$ & Atributo \\
\hline$\rho 1$ & 5 & 5 & $\mathrm{~F}$ \\
\hline$\rho 2$ & 4 & 5 & $\mathrm{~F}$ \\
\hline$\rho 3$ & 3 & 4 & $\mathrm{NF}$ \\
\hline$\rho 4$ & 3 & 3 & $\mathrm{NF}$ \\
\hline$\rho 5$ & 5 & 4,1 & $\mathrm{NF}$ \\
\hline$\rho 6$ & 5 & 4,1 & $\mathrm{NF}$ \\
\hline$\rho 7$ & 2,5 & 6 & $\mathrm{NF}$ \\
\hline$\rho 8$ & 2,5 & 6 & $\mathrm{NF}$ \\
\hline
\end{tabular}




\subsection{Teoria dos Conjuntos Nebulosos}

A Teoria dos Conjuntos Nebulosos foi introduzida por Lotfi Asker Zadeh em 1965 (Zadeh, 1965 e 1978). Essa teoria é uma extensão da lógica convencional (booleana), para introduzir o conceito de verdade não absoluta, e funciona como uma ferramenta para tratar imprecisões na linguagem natural. A matemática nebulosa é uma tentativa de aproximar a precisão característica da matemática à inerente imprecisão do mundo real. $\mathrm{O}$ número nebuloso não surge, normalmente, de observações reais, mas de conceitos ou concepções mais ou menos conhecidos. A Teoria dos Conjuntos Nebulosos é uma maneira de representar imprecisões encontradas, as quais os seres humanos tratam com grande habilidade, normalmente existentes em problemas reais, os quais os conjuntos tradicionais não podem representar adequadamente (Gomes, Gomes \& Teixeira, 2002).

Logo, os números nebulosos são uma alternativa à noção de conjunto de números reais e lógicos, que possui origem na filosofia grega. A Teoria dos Conjuntos Nebulosos está associada à abstração e à generalização, e possibilita a representação de conceitos vagos e imprecisos, porém mantendo a precisão matemática no tratamento.

Vislumbra-se a utilização da Teoria dos Conjuntos Nebulosos no auxílio aos negociadores para, no campo das possibilidades, procurar-se responder às seguintes perguntas:

(a) Qual a possibilidade de uma particular negociação alcançar um resultado de consenso?

(b) Qual a possibilidade do negociador $\mathrm{x}$ conseguir junto ao negociador y um dado resultado?

Observação: existe neste caso o pressuposto que é possível obter-se um resultado de consenso. Pode ocorrer em um processo de negociação que não seja possível encontrar-se um consenso ou meio-termo. Estes pontos inegociáveis normalmente são os ditos "pontos de honra". Esta situação pode acarretar:

- Saída do negociador do processo, que pode ou não inviabilizar a negociação;

- Retirada, quando possível, deste ponto conflitante da negociação;

- Postergar este ponto, com todas as alternativas existentes; não negociá-las e prosseguir a negociação de outros pontos, com o compromisso de voltar a ele no futuro; ou

- Postergar todo o processo de negociação.

\section{Utilização de Metodologias do AMD para Negociação ou Decisão em Grupo}

O AMD permite a priorização de alternativas em uma situação de critérios conflitantes, buscando satisfazer as restrições, com objetivos conflitantes, ou seja, uma solução de compromisso. Assim sendo, o AMD pode fornecer métodos para o apoio à negociação e/ou decisão em grupo (Buchanan \& Gardiner, 2003).

Assumindo que todo sistema computadorizado de suporte à negociação tem, ou deveria ter, embutido nele, um modelo matemático orientado para tomada de decisão, bem como a busca do consenso, pode-se conceituar o estudo sistemático de processos de negociação e resolução de conflitos como uma subdivisão do AMD, uma vez que um tal processo acarreta uma decisão, naturalmente multicritério, em grupo (Gomes, 1991). Portanto, sistemas de suporte à negociação (SSN) são sistemas de apoio à decisão negociada (SADN) (Gomes \& Gomes, 
1999). Eventualmente, mais de uma decisão pode resultar do processo de negociação, o qual não conduz obrigatoriamente a um consenso, e nem a uma relação de dominância ou fronteira Pareto-ótima. Em negociação, por vezes fatores políticos se sobrepõem a fatores técnicos, e neste caso uma fronteira de eficiência, que só considere fatores técnicos, por vezes, é impossível de ser alcançada (Jelassi, Kersten \& Zionts, 1990).

O uso de um sistema de apoio à negociação só é possível se for reconhecida a existência de um ou múltiplos problemas (comuns a ambos) e os atores envolvidos se conscientizarem da necessidade de usar um sistema que permita a "coletivização" da decisão (Gomes \& Gomes, 2003 e 2005).

Os temas envolvidos na negociação, por sua vez, podem ou não ser possíveis de serem negociados, dentro de uma margem de tolerância. Ao longo do processo o acordo entre as partes pode simplesmente indicar o final do processo, do qual a negociação tanto pode ser ganha-ganha, como ganha-perde - no caso mais simples, mas nem por isso menos ilustrativo, de terem-se apenas dois negociadores (Gomes, Gomes \& Moreira, 1998).

Assim sendo, diante de toda essa eventual complexidade, os SSN praticamente podem lançar mão de modelagem analítica de tratamento da informação imprecisa combinados com métodos do AMD. Essas técnicas e métodos, no entanto, só muito ingenuamente poderiam ser utilizados externamente aos negociadores; espera-se, por conseguinte, que cada negociador tenha acesso a uma base de conhecimento que inclua pelo menos um método analítico.

Para Matsatsinis \& Samaras (2001) o uso do AMD consiste em:

$\Rightarrow$ Estruturar o processo da decisão, identificando regras de decisão, critérios e pesos dos critérios;

$\Rightarrow$ Representar as múltiplas visões dos atores da decisão;

$\Rightarrow$ Grupar preferências elicitando os valores do grupo.

Salienta-se que o AMD começa a busca da(s) alternativa(s) de solução do problema pelas soluções e alternativas não-dominadas (Marmol, Puerto \& Fernández, 2002).

A literatura identifica algumas aproximações para a decisão em grupo na visão multicritério, tais como (Leya-López \& Fernandez-González, 2003):

$\Rightarrow$ Os atores de decisão identificam as alternativas, critérios, pesos dos critérios, e demais parâmetros julgados importantes, a partir de perguntas individuais, e depois os apresenta aos grupos envolvidos. A partir disto, por meio de ferramentas e/ou metodologias, buscam chegar a uma opinião coletiva; e, posteriormente, faz-se a ordenação das alternativas utilizando um método ou metodologia previamente acordados;

$\Rightarrow$ Cada ator de decisão identifica os parâmetros julgados importantes e, posteriormente, qual método ou metodologia mais lhe agrada, faz a ordenação das alternativas e, a seguir, cada ator traz a sua ordenação e, a partir das ordenações dos vários decisores busca-se o consenso.

Matsatsinis \& Samaras (2001) afirmam que os métodos do AMD são uma excelente ferramenta para redução (apoio à diminuição) dos conflitos interpessoais quando o objetivo é obter o consenso entre grupos ou pessoas, senão, pelo menos, buscando a minimização de conflitos individuais. Um grande obstáculo a qualquer processo de decisão em grupo e mais 
ainda na negociação é que cada participante tem a sua percepção do problema alterada de acordo com os resultados possíveis da decisão ou negociação. A percepção das diferenças de visões do problema e/ou preferências individuais aparece quando se pretende criar um modelo que agregue as preferências do grupo, baseado nas preferências individuais (modelagem descrita em 3.2 Modelo do Hiperjogo).

O AMD, em decisões em grupo, é aplicável na:

$\Rightarrow$ Definição inicial do problema, criação de regras gerais de decisão, e normas do grupo;

$\Rightarrow$ Elicitação de preferências individuais, e posteriormente agregando estas para gerar as opiniões dos subgrupos e grupos, que refletirão os pontos de vista individuais que os criaram;

$\Rightarrow$ Priorização das alternativas, e avaliação dos critérios com pesos (Zhang \& Yang, 2001; Zhang, Jason \& Chong, 2004); e

$\Rightarrow$ Resolução dos conflitos, seja de importância dos critérios, seja na "função objetivo".

Este artigo apresentará em seqüência, em um exemplo, pelo estudo de dois casos, comparando os resultados da aplicação de Metodologias do AMD, uma proposta de uso do AMD na resolução de problemas (e conseqüente minimização de conflitos). O AMD é uma área dinâmica do conhecimento e da pesquisa, orientada em apoiar os decisores e os negociadores, auxiliando na estruturação dos problemas, permitindo expandir a argumentação e ampliando a capacidade de aprendizagem e compreensão (Choo \& Wedley, 2004).

\subsection{Primeiro estudo - localização de planta energética}

Utilizando a Metodologia Multicritério de Apoio à Decisão THOR, como mais uma proposta de modelagem analítica, aplicando e comparando nos exemplos dos artigos de Leya-López \& Fernandez-González (2003) e de Takeda (2001), proceder-se-á a uma comparação dos resultados do software THOR com as sugestões do ELECTRE-GD (variação do ELECTRE III), Prometthee II, ELECTRE III, e AHP “ternary” (variação do AHP).

A Metodologia THOR foi implementada em um software com mesmo nome, cujos conceitos estão em Gomes (1999 e 2005) e Alencar, Costa \& Gomes (2005). O software THOR e a metodologia que lhe dá suporte foram desenvolvidos em Gomes (1999) com o propósito de levar em consideração a incerteza/imprecisão da informação na ordenação das alternativas. $\mathrm{O}$ THOR ordena as alternativas buscando a(s) alternativa(s) que maximizem o ganho e minimizem a imprecisão da(s) informação(ões).

Aplicações do THOR na solução de problemas reais estão descritas em: Xavier et al. (2004), Nunes et al. (2003) e Cardoso et al. (2004).

No estudo será proposto o uso de algumas metodologias do AMD em uma modelagem analítica para Negociação e Decisão em Grupo, onde deve-se:

- Agregar as preferências individuais em uma preferência do grupo;

- Ordenar o grupo de alternativas inicialmente existentes no processo;

- Auxiliar o processo de contração das alternativas, eliminando as menos relevantes para o grupo;

- Modelar o problema e a busca da "melhor" solução. 
Definição (simplificada) do problema: identificação do melhor local para construção de uma usina de energia na Europa, onde as alternativas disponíveis (em países) constam da Tabela VII, e os decisores são os constantes na Tabela VIII; os critérios a serem usados na comparação das alternativas são descritos na Tabela IX. As demais informações, relevantes do problema, apresentados no artigo de Leya-López \& Fernandez-González (2003) estão descritas nas Tabelas X, XI e XII.

Tabela VII - Alternativas.

\begin{tabular}{|l|l|l|l|l|l|l|l|l|l|l|l|}
\hline a1 & Itália & a2 & Bélgica & a3 & Alemanha & a4 & Suécia & a5 & Áustria & a6 & França \\
\hline
\end{tabular}

Tabela VIII - Decisores.

\begin{tabular}{|c|c|c|c|c|c|c|c|}
\hline DM1 & $\begin{array}{c}\text { EP - Produção } \\
\text { de energia }\end{array}$ & DM2 & $\begin{array}{c}\text { ENV - Meio } \\
\text { ambiente }\end{array}$ & DM3 & FIN - Finanças & DM4 & TU - Taxas \\
\hline
\end{tabular}

Tabela IX - Critérios.

\begin{tabular}{|c|c|c|c|c|c|}
\hline $\mathrm{C} 1$ & $\begin{array}{l}\text { MP - Número de } \\
\text { engenheiros }\end{array}$ & $\mathrm{C} 5$ & $\begin{array}{c}\text { VIL - Cidades para } \\
\text { avaliar } \\
\end{array}$ & C9 & SOC - Impacto social \\
\hline $\mathrm{C} 2$ & $\begin{array}{c}\text { POW - Energia em } \\
\text { MW }\end{array}$ & C6 & $\begin{array}{c}\text { DAN - Perigo para o } \\
\text { ambiente }\end{array}$ & \multirow{2}{*}{ C10 } & \multirow{2}{*}{$\begin{array}{l}\text { TPT - Facilidade de } \\
\text { transportes para a usina }\end{array}$} \\
\hline $\mathrm{C} 3$ & $\begin{array}{l}\mathrm{CC}-\text { Custo da } \\
\text { construção }\end{array}$ & $\mathrm{C} 7$ & $\begin{array}{l}\text { SEC - Nível de } \\
\text { segurança }\end{array}$ & & \\
\hline $\mathrm{C} 4$ & $\begin{array}{c}\text { MT - Custo anual de } \\
\text { manutenção }\end{array}$ & $\mathrm{C} 8$ & $\begin{array}{c}\mathrm{CO} \text { - Emissão de } \\
\text { monóxido de carbono }\end{array}$ & $\mathrm{C} 11$ & FIN - Retorno financeiro \\
\hline
\end{tabular}

Tabela $\mathbf{X}$ - Desempenho das alternativas nos critérios.

\begin{tabular}{|c|c|c|c|c|c|c|c|c|c|c|c|}
\cline { 2 - 12 } \multicolumn{1}{c|}{} & C1 & C2 & C3 & C4 & C5 & C6 & C7 & C8 & C9 & C10 & C11 \\
\hline a1 & 80 & 500 & 1000 & 5,2 & 8 & 0,5 & 9 & 0 & 2 & 300 & 4200 \\
\hline a2 & 55 & 580 & 250 & 3 & 1 & 4 & 3 & 5 & 8 & 175 & 900 \\
\hline $\mathrm{a} 3$ & 83 & 600 & 450 & 3,8 & 4 & 3,5 & 7 & 65 & 6 & 125 & 850 \\
\hline $\mathrm{a} 4$ & 40 & 450 & 1000 & 7,5 & 7 & 0 & 10 & 0 & 10 & 450 & 900 \\
\hline $\mathrm{a} 5$ & 52 & 880 & 900 & 3 & 3 & 4,5 & 2 & 10 & 5 & 150 & 750 \\
\hline $\mathrm{a} 6$ & 94 & 960 & 950 & 3,6 & 5 & 3,5 & 4 & 10 & 3 & 250 & 2000 \\
\hline
\end{tabular}

Tabela XI - Pesos dos critérios por decisor.

\begin{tabular}{|c|c|c|c|c|c|c|c|c|c|c|c|}
\cline { 2 - 12 } \multicolumn{1}{c|}{} & C1 & C2 & C3 & C4 & C5 & C6 & C7 & C8 & C9 & C10 & C11 \\
\hline DM1 & 1 & 2 & 1 & 1 & 1 & 0 & 1 & 0 & 0 & 0 & 0 \\
\hline DM2 & 0 & 0 & 0 & 0 & 1 & 1 & 1 & 1 & 0 & 0 & 0 \\
\hline DM3 & 1 & 0 & 1 & 1 & 0 & 0 & 0 & 0 & 0 & 0 & 3 \\
\hline DM4 & 1 & 0 & 0 & 0 & 0 & 0 & 1 & 0 & 1 & 1 & 0 \\
\hline
\end{tabular}


Tabela XII - Parâmetros de indiferença e preferência estrita para os critérios.

\begin{tabular}{|c|c|c|c|c|c|c|c|c|c|c|c|}
\cline { 2 - 12 } \multicolumn{1}{c|}{} & $\mathrm{C} 1$ & $\mathrm{C} 2$ & $\mathrm{C} 3$ & $\mathrm{C} 4$ & $\mathrm{C} 5$ & $\mathrm{C} 6$ & $\mathrm{C} 7$ & $\mathrm{C} 8$ & $\mathrm{C} 9$ & $\mathrm{C} 10$ & $\mathrm{C} 11$ \\
\hline $\mathrm{p}$ & 10 & 300 & 500 & 6 & 0 & 5 & 0 & 5 & 2 & 100 & 0 \\
\hline $\mathrm{q}$ & 10 & 0 & 50 & 1 & 0 & 0 & 0 & 0 & 2 & 0 & 0 \\
\hline
\end{tabular}

Para efeitos de comparação, neste estudo, utilizando-se o THOR usar-se-á dois algoritmos denominados S2 e S3, e as informações constantes nas Tabelas VII a XII. Será inicialmente feita a ordenação das alternativas por decisor. Os critérios em que o decisor atribuiu peso 0 não são incluídos na ordenação das alternativas pelo respectivo decisor. Por exemplo, o Decisor 1 (DM1) só considera os critérios C1 a C5 e C7 (Tabela XI).

\begin{tabular}{|l|l|l|}
\hline \multicolumn{3}{|c|}{ localização planta energetica } \\
\hline \hline & Sort S2 & Score \\
\hline 1 & A5 - Austria & 3,142857 \\
\hline 2 & A2 - Bélgica & 3,071429 \\
\hline 3 & A3 - Alemanha & 2,5 \\
\hline 4 & A6 - França & 2,428571 \\
\hline 5 & A1 - Itália & 0,5 \\
\hline $\mathbf{6}$ & A4 - Suécia & 0,5 \\
\hline
\end{tabular}

\begin{tabular}{|l|l|l|}
\hline \multicolumn{3}{|c|}{ localizaçäo planta energetica } \\
\hline & Sort S3 & Score \\
\hline 1 & A2 - Bélgica & 3,428571 \\
\hline 2 & A5 - Austria & 3,428571 \\
\hline 3 & A3 - Alemanha & 2,857143 \\
\hline 4 & A6 - França & 2,571429 \\
\hline 5 & A1 - Itália & 0,571429 \\
\hline 6 & A4 - Suécia & 0,571429 \\
\hline
\end{tabular}

Figura 1 - Ordenação S2 e S3 para o DM1.

Para o DM1, a ordenação é a apresentada na Figura 1 e tem-se, a partir da observação das ordenações dos dois algoritmos, a sua preferência como: $(a 5, a 2)>a 3>a 6>(a 1=a 4)$.

\begin{tabular}{|l|l|l|}
\hline \multicolumn{3}{|c|}{ localização planta energetica } \\
\hline \hline & Sort S2 & Score \\
\hline 1 & A4 - Suécia & 3,75 \\
\hline 2 & A1 - Itália & 3 \\
\hline 3 & A2 - Bélgica & 2 \\
\hline 4 & A3 - Alemanha & 1,5 \\
\hline 5 & A6 - França & 1,5 \\
\hline 6 & A5 - Austria & 1 \\
\hline & & \\
\hline
\end{tabular}

\begin{tabular}{|l|l|l|}
\hline \multicolumn{3}{|c|}{ localização planta energetica } \\
\hline & Sort S3 & Score \\
\hline 1 & A4 - Suécia & 4 \\
\hline 2 & A1 - Itália & 3 \\
\hline 3 & A2 - Bélgica & 2 \\
\hline 4 & A3 - Alemanha & 1,75 \\
\hline 5 & A6 - França & 1,25 \\
\hline 6 & A5 - Austria & 0,5 \\
\hline
\end{tabular}

Figura 2 - Ordenação S2 e S3 para o DM2.

Para o DM2, a ordenação é a apresentada na Figura 2 e tem-se: a4 > a1 > a2 > (a3, a6) > a5. 


\begin{tabular}{|l|l|l|}
\hline \multicolumn{3}{|c|}{ localizaçäo planta energetica } \\
\hline & Sort S2 & Score \\
\hline 1 & A2 - Bélgica & 3 \\
\hline 2 & A1 - Itália & 2,833333 \\
\hline 3 & A6 - França & 2,333333 \\
\hline 4 & A4 - Suécia & 1,833333 \\
\hline 5 & A3 - Alemanha & 1,666667 \\
\hline 6 & A5 - Austria & 1 \\
\hline & & \\
\hline
\end{tabular}

\begin{tabular}{|l|l|l|}
\hline \multicolumn{3}{|l|}{ localização planta energetica } \\
\hline & Sort S3 & Score \\
\hline 1 & A2 - Bélgica & 3,333333 \\
\hline 2 & A1 - Itália & 3,166667 \\
\hline 3 & A6 - França & 2,833333 \\
\hline 4 & A4 - Suécia & 2 \\
\hline 5 & A3 - Alemanha & 0,833333 \\
\hline 6 & A5 - Austria & 0,5 \\
\hline
\end{tabular}

Figura 3 - Ordenação S2 e S3 para o DM3.

Para o DM3, a ordenação é a apresentada na Figura 3 e tem-se: a2 > a1 > a6 > a4 > a3 > a5.

\begin{tabular}{|l|l|l|}
\hline \multicolumn{3}{|c|}{ localização planta energetica } \\
\hline & Sort S2 & Score \\
\hline 1 & A4 - Suécia & 3,75 \\
\hline 2 & A1 - Itália & 2,5 \\
\hline 3 & A6 - França & 2,5 \\
\hline 4 & A3 - Alemanha & 2 \\
\hline 5 & A2 - Bélgica & 1,25 \\
\hline 6 & A5 - Austria & 0,5 \\
\hline
\end{tabular}

\begin{tabular}{|l|l|l|}
\hline \multicolumn{3}{|c|}{ localização planta energetica } \\
\hline & Sort S3 & Score \\
\hline 1 & A4 - Suécia & 3,75 \\
\hline 2 & A1 - Itália & 3 \\
\hline 3 & A6 - França & 2 \\
\hline 4 & A3 - Alemanha & 1,75 \\
\hline 5 & A2 - Bélgica & 1,5 \\
\hline 6 & A5 - Austria & 0 \\
\hline
\end{tabular}

Figura 4 - Ordenação S2 e S3 para o DM4.

Para o DM4, a ordenação é a apresentada na Figura 4 e tem-se: a4 $>(a 1, a 6)>$ a3 $>$ a2 $>$ a5. Ocorre um conflito do DM4 com os demais decisores, pois o DM4 julga importante maximizar o número de engenheiros (critério c1), pois DM4 considera importante maximizar o número de empregos, ao contrário dos demais decisores que vê a contratação de engenheiros como algo a ser minimizado. Para o DM4, olhando apenas o critério c1, a melhor alternativa é a a6, e na preferência dos demais decisores a melhor alternativa é a a4. Esta informação foi colocada no THOR e nas demais metodologias.

Tabela XIII - Preferências das alternativas por decisor.

\begin{tabular}{|c|c|c|c|}
\hline DM1 & DM2 & DM3 & DM4 \\
\hline \multirow{2}{*}{$\mathrm{a} 5 ; \mathrm{a} 2$} & $\mathrm{a} 4$ & $\mathrm{a} 2$ & $\mathrm{a} 4$ \\
\cline { 2 - 3 } & $\mathrm{a} 1$ & $\mathrm{a} 1$ & \multirow{2}{*}{$\mathrm{a} 1 ; \mathrm{a} 6$} \\
\hline $\mathrm{a} 3$ & $\mathrm{a} 2$ & $\mathrm{a} 6$ & \\
\hline $\mathrm{a} 6$ & \multirow{2}{*}{$\mathrm{a} 3 ; \mathrm{a} 6$} & $\mathrm{a} 4$ & $\mathrm{a} 3$ \\
\cline { 3 - 4 } & & $\mathrm{a} 3$ & $\mathrm{a} 2$ \\
\cline { 2 - 4 } $\mathrm{a} 1 ; \mathrm{a} 4$ & $\mathrm{a} 5$ & $\mathrm{a} 5$ & $\mathrm{a} 5$ \\
\hline
\end{tabular}


A Tabela XIII deve ser utilizada para converter as preferências individuais em coletivas gerando o produto final que é a agregação das preferências dos decisores. A ordenação individual dos decisores, obtida pelo THOR, e apresentada na Tabela XIII, está coerente com as ordenações individuais descritas por Leya-López \& Fernandez-González (2003).

$\mathrm{Na}$ modelagem, este foi o estágio da aprendizagem (Etapa 1) segundo Matsatsinis \& Samaras (2001), e o passo definido por Leya-López \& Fernandez-González (2003) como "fornecimento de informações e preferências".

Observando a Tabela XIII as alternativas a1 e a2 estão na metade superior da mesma para três decisores; as alternativas a4 e a6 estão para dois decisores no primeiro grupo, e para dois no segundo grupo; e as alternativas a3 e a5 estão no segundo grupo para três decisores. Transparece que existe um grande conflito em relação à alternativa a5 para o DM1 e os demais decisores, uma vez que DM1 a considera uma das duas melhores alternativas, e os demais decisores a consideram como pior.

Pela aproximação descrita por Leya-López \& Fernandez-González (2003) como "cada ator traz a sua ordenação" e depois busca-se a agregação das preferências, observando a Tabela XIII, teríamos, como primeira tentativa de agregação: $(a 1, a 2)>(a 4, a 6)>(a 3$, a5). Como descrito anteriormente, o AMD deve ser utilizado para identificar preferências individuais e entender como o decisor percebe o problema.

Como sugestão inicial para ordenar as alternativas descritas na Tabela VII, será feita uma média aritmética dos pesos dos critérios fornecidos pelos decisores (Tabela XI), e a função de pertinência (necessária no THOR), como quantificador da imprecisão da informação, será definida como "a concordância do grupo com a média". Esta aproximação, com a utilização do THOR gera a Figura 5. Esta aproximação parte do pressuposto que todos os decisores explicitaram de forma verdadeira as suas preferências. Assim sendo os Vetores $V_{i}$ são iguais aos Vetores $\mathrm{V}_{\mathrm{iq}}$ (descritos no modelo do Hiperjogo).

O modelo do Hiperjogo torna-se importante para lembrar aos analistas e decisores, que "acreditar sem sombra de dúvidas" nas informações dos outros jogadores pode ser uma aproximação simplista.

localizaçäo planta energetica
\begin{tabular}{|l|l|l}
\hline Insert criterion membership - function & Weight Membership Function \\
\hline Criterion Name & Criterion Weight & 0,75 \\
\hline C1-MP-Engenheiro & 0,75 & 0,25 \\
\hline C2-POW - Energia & 0,5 & 0,5 \\
\hline C3-CC - C Construção & 0,5 & 0,5 \\
\hline C4-HT - C Manutenção & 0,5 & 0,5 \\
\hline C5-VIL - Cidades & 0,5 & 0,25 \\
\hline C6-DAN - Ambiente & 0,25 & 0,75 \\
\hline C7-SEC - Segurança & 0,75 & 0,25 \\
\hline C8-CO - Carbono & 0,25 & 0,25 \\
\hline C9-SOC - Social & 0,25 & 0,25 \\
\hline C10-TPT - Transporte & 0,25 & 0,25 \\
\hline C11-FIN - Financeiro & 0,75 & \\
\hline
\end{tabular}

Figura 5 - Critérios, pesos e pertinências. 
Utilizando o THOR para a segunda aproximação descrita por Leya-López \& FernandezGonzález (2003), ou seja, fazer inicialmente uma agregação dos valores dos decisores (Figura 5), e posteriormente fazer uma ordenação, com estes valores agregados. Serão aplicados os dados da Figura 5 em substituição à Tabela XI, onde foi feita uma média aritmética dos pesos, dos critérios pelos decisores, e criada uma função de pertinência (função esta definida na Teoria dos Conjuntos Nebulosos (Gomes, Gomes \& Teixeira, 2002; Zadeh, 1965 e 1978)) que informa a concordância do grupo com o peso atribuído. Obtém-se a ordenação constante na Figura 6.
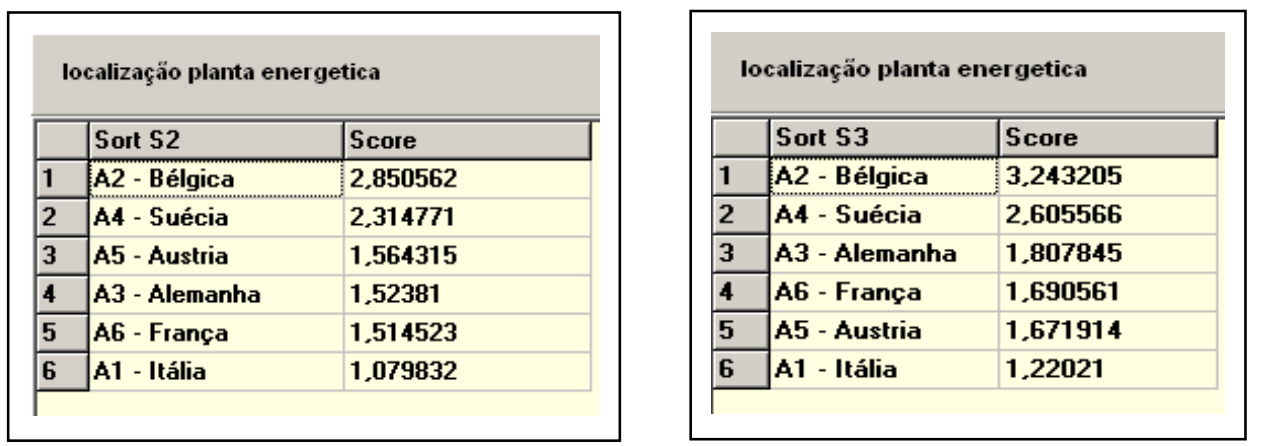

Figura 6 - Ordenação S2 e S3.

Leya-López \& Fernandez-González (2003) apresentam a sugestão do ELECTRE GD, no caso: $\mathrm{a} 2>\mathrm{a} 1>\mathrm{a} 4>\mathrm{a} 3>\mathrm{a} 6>\mathrm{a} 5$. Os autores informam que usando o PROMETHEE II foi gerada a ordenação a2 $>$ a3 $>$ a1 $>$ a4 $>$ a6 $>$ a5.

A análise de sensibilidade destes dois métodos levaria à conclusão que: a2 > (a1, a3, a4) > a6 $>$ a5. Este resultado, se comparado ao primeiro obtido com o uso do THOR [(a1, a2) $>$ $(\mathrm{a} 4, \mathrm{a} 6)>(\mathrm{a} 3, \mathrm{a} 5)]$ tem em comum que teríamos a2 como a melhor e a5 como a pior. O THOR iria sugerir a ampliação da discussão em torno de a1 e a2, e o descarte de a3 e a5. A análise ELECTRE / PROMETHEE II sugere a escolha de a2, e o descarte de a6 e a5. Identifica-se assim uma coerência no uso dos métodos ELECTRE GD, PROMETHEE II e o THOR na escolha de a2 e descarte de a5.

A agregação às preferências dos pesos dos decisores pela simples média aritmética e a criação da função de pertinência gerou a2 $>$ a4 $>(a 5, a 3, a 6)>$ al (Figura 6), que teve como grande mérito indicar como melhor alternativa a a2 (tanto pelo algoritmo S2 como S3), que foi a mesma indicada com o uso do ELECTRE GD e o PROMETHEE II.

Depreende-se que a aplicação dos métodos multicritério permite efetivamente uma agregação prévia das informações, ordenação das alternativas, descarte de algumas, e concentração das atenções e outras. O THOR, o PROMETHEE II e o ELECTRE GD foram coerentes em todas as aproximações para indicar que a alternativa a2 deveria estar no grupo de alternativas dominantes, o que nos leva a crer que esta seria a alternativa escolhida, que era a preferida pelo DM1 e DM3, e a terceira preferida pelo DM2, que conjuntamente com o DM4 preferiam a a4. Isto explica por que o THOR quando agregou as informações colocou a2 e a4 como preferidas.

Salienta-se que a escolha do método interfere nas ordenações. 


\subsection{Segundo estudo - compra de terreno}

Em Takeda (2001) o autor propõe uma variação do AHP denominado "ternary", onde o AHP ternary seria aplicado para pseudocritérios. Neste mesmo artigo é feita uma comparação deste AHP com o ELECTRE III, aplicando no problema, onde os dados das alternativas e dos critérios estão na Tabela XIV.

Definição (simplificada) do problema: identificação do melhor terreno para compra, para posterior utilização em uma construção.

Tabela XIV - Critérios, alternativas, pesos, parâmetros de indiferença e preferência estrita e V (veto).

\begin{tabular}{||c|c|c|c|c|c||}
\hline Critérios & Preço da terra & $\begin{array}{c}\text { Custo do } \\
\text { transporte do } \\
\text { material de } \\
\text { construção }\end{array}$ & $\begin{array}{c}\text { Reserva para o } \\
\text { meio ambiente }\end{array}$ & $\begin{array}{c}\text { Número de } \\
\text { residentes que } \\
\text { são } \\
\text { incomodados }\end{array}$ & $\begin{array}{c}\text { Grau de } \\
\text { competitividade } \\
\text { com outras } \\
\text { opções de férias }\end{array}$ \\
\hline \hline Alternativas & $\begin{array}{c}\text { \$ por metro } \\
\text { quadrado }\end{array}$ & $\begin{array}{c}\text { \$ por 1000 } \\
\text { km }\end{array}$ & $\begin{array}{c}\text { Avaliação } \\
\text { qualitativa }\end{array}$ & $\begin{array}{c}\text { Avaliação } \\
\text { qualitativa }\end{array}$ & $\begin{array}{c}\text { Avaliação } \\
\text { qualitativa }\end{array}$ \\
\hline $\mathrm{a} 1$ & -120 & -284 & 5 & 3,5 & 18 \\
\hline $\mathrm{a} 2$ & -150 & -269 & 2 & 4,5 & 24 \\
\hline $\mathrm{a} 3$ & -100 & -413 & 4 & 5,5 & 17 \\
\hline $\mathrm{a} 4$ & -60 & -596 & 6 & 8,0 & 20 \\
\hline $\mathrm{a} 5$ & -30 & -1321 & 8 & 7,5 & 16 \\
\hline $\mathrm{a} 6$ & -80 & -734 & 5 & 4,0 & 21 \\
\hline $\mathrm{a} 7$ & -45 & -982 & 7 & 8,5 & 13 \\
\hline \hline Pesos & 25 & 45 & 10 & 12 & 8 \\
\hline $\mathrm{P}$ & 40 & 350 & 3 & 3,5 & 1 \\
\hline $\mathrm{Q}$ & 15 & 80 & 1 & 0,5 & 8 \\
\hline $\mathrm{V}$ & 100 & 850 & 5 & 4,5 & \\
\hline \hline
\end{tabular}

A ordenação AHP gerou que $\mathrm{a} 4>(\mathrm{a} 1=\mathrm{a} 2=\mathrm{a} 3)>(\mathrm{a} 7=\mathrm{a} 5)>\mathrm{a} 6$; e a ordenação do ELECTRE III gerou que:

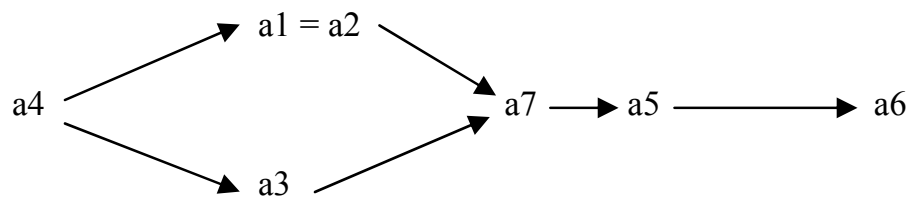

Analisando as ordenações do AHP ternary e ELECTRE III, pode-se concluir que a4 $>($ a1, a2, a3 $)>(a 7, a 5)>$ a6. Em processo de negociação e/ou decisão em grupo, fica-se com as alternativas a4, a1, a2 e a3 descartando as demais. THOR no algoritmo S2 gerou a ordenação $(\mathrm{a} 2, \mathrm{a} 4)>\mathrm{a} 1>\mathrm{a} 7>\mathrm{a} 3>\mathrm{a} 6>\mathrm{a} 5$; e no algoritmo $\mathrm{S} 3$ gerou a ordenação $\mathrm{a} 2>\mathrm{a} 4>$ a1 $>$ a7 $>$ a3 $>$ a6 $>$ a5. 
Utilizando o THOR fica-se com as alternativas a2, a4 e a1 descartando as demais. Utilizando o THOR alternativa a3 não seria considerada.

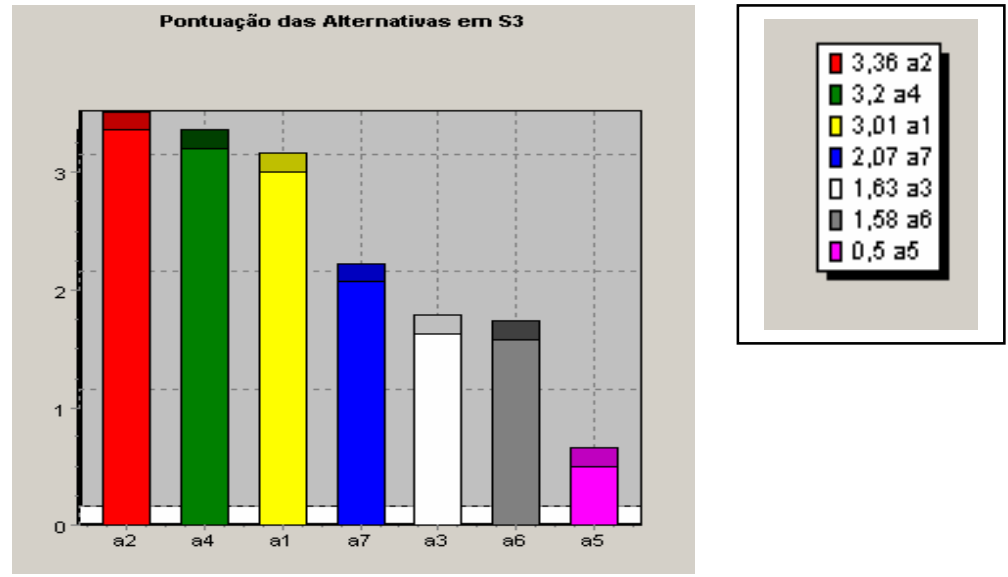

Figura 7 - Representação gráfica da ordenação S3.

Observação: neste problema já existe um consenso sobre a importância relativa dos critérios; (pesos atribuídos) buscou-se pelo uso de três métodos multicritério; mostrar-se que métodos diferentes, mesmo usando os mesmos dados, podem gerar ordenações diferentes, e assim gerar ordenações/sugestões diferentes. Torna-se assim importante a aplicação de mais de um método para tentar identificar, de forma mais segura, qual(is) a(s) alternativa(s) dominada(s).

\section{Conclusões e Recomendações}

Este artigo buscou propor modelagens para utilização em decisão em grupo ou negociação, e no caso particular da informação imprecisa, em um quadro Multicritério, propôs dentro uma função denominada "Função Negociação", e incluiu de forma nova uma variável denominada o "peso do negociador".

A "Função Negociação" está inserida em uma nova Metodologia para apoiar o processo de negociação, e o exemplo numérico empregando a nova Metodologia mostrou que a TCA é uma ferramenta útil para expandir o limite da cognição do ser humano, e permitir ampliar a fronteira humana do conhecimento, pois esta fronteira poderá ser progressivamente estendida à medida em que forem eliminados da negociação/decisão os critérios julgados redundantes. Com isso, os critérios remanescentes, uma vez que caracterizem uma família coerente de critérios - satisfazendo, por conseguinte, os princípios de exaustividade, coesão e nãoredundância poderão ter suas importâncias efetivas avaliadas e/ou reavaliadas, assim como novos critérios poderão ser identificados e inseridos no processo.

Por outro lado, uma vez que o racional para um negociador não é necessariamente para um conjunto de negociadores - não obrigatoriamente constituintes de uma coalizão - identificase assim um novo campo para aplicação da TCA, caracterizando-se como indiscernível o que é racional para um negociador e não o é quando o mesmo insere-se em um grupo de negociadores. 
Foi proposto também o uso conjunto da TCA com a Teoria da Utilidade em processos de negociação.

$\mathrm{O}$ uso da modelagem analítica com utilização de metodologias do AMD mostrou-se eficaz para:

a) Agregar as preferências individuais para posterior criação da preferência do grupo;

b) Identificar as alternativas com menor preferência bem como as que possuem maior preferência.

Verificou-se ser eficiente a agregação das preferências elicitando as ordenações individuais dos decisores, e depois confrontando-as; ou criando uma ordenação do grupo e depois apresentando-as aos decisores.

Este estudo mostrou que a ordenação de preferências das alternativas pode ser usada na decisão em grupo para:

- escolha da(s) "melhor(es)" alternativa(s);

- eliminação da(s) "pior(es)" alternativa(s).

Na negociação, o AMD pode auxiliar a minimizar o tempo do processo de contração $e$ expansão de alternativas, eliminando o grupo das piores alternativas, do processo decisório, ou selecionando o grupo das melhores alternativas para mantê-las no processo decisório.

Este estudo demonstrou que as metodologias do AMD podem ser usadas como auxílio à negociação e à decisão em grupo, para dar transparência ao processo decisório e/ou identificar os conflitos. Verificou-se que as duas aproximações, usadas pelo AMD, descritas por Leya-López \& Fernandez-González (2003), são robustas para solução dos problemas.

A compilação das propostas, de procedimentos, sugeridos pelos autores referenciados neste artigo, e descritos em 2. Considerações sobre Negociação e Decisão em Grupo podem ser resumidas/agregadas nos seguintes procedimentos:

a) identificar e coletar as informações disponíveis, fazer as perguntas necessárias;

b) identificar as preferências individuais e convertê-las em decisão coletiva;

c) verificar, caso seja negociação, se esta é coercitiva ou acomodativa;

d) identificar conflitos e coalizões, e buscar cultivar a confiança;

e) fazer coalizões quando necessário for;

f) identificar se o processo é local ou remoto; se é temporal; se é cooperativo, democrático, hierárquico ou conflitante;

g) identificar se ocorrem coletivas preferências (ou não preferências ou indiferenças), e onde estão estas preferências;

h) verificar onde estão as imprecisões, indeterminações e incertezas, e identificar como tratá-las;

i) identificar como será procedida a agregação de informações; se será por indivíduo, por grupo, ou pelos dois processos; quais metodologias serão utilizadas para agregação;

j) estudar/identificar/saber qual(is) a(s) limitação(ões) da(s) metodologia(s) utilizada(s);

k) verificar se existe uma pessoa escolhida pelo grupo para auxiliar na busca pelo consenso;

1) identificar qual será a estratégia e a tática na negociação; 
m) revele informações, que julgar pertinente, de forma estratégica;

n) verificar quais são as metas, critérios, alternativas e importâncias atribuídas a estes parâmetros;

o) verificar se a etapa de aprendizagem foi concluída;

p) identificar quais novas propostas surgiram durante a aprendizagem; faça múltiplas ofertas simultaneamente;

q) verificar se as múltiplas visões foram identificadas durante a aprendizagem;

r) buscar acordos pós-acordos.

\section{Referências Bibliográficas}

(1) Alencar, L.H.; Costa, A.P.C.S. \& Gomes, C.F.S. (2005). Gerenciamento de projeto na construção civil utilizando o apoio multicriterio a decisão. Revista de la Escuela de Perfeccionamiento en Investigacion Operativa, Buenos Aires, 26, 163-186, novembro.

(2) Bazerman, M.H. (2004). Processo Decisório. Tradução da Quinta Edição, Editora Campus, Rio de Janeiro.

(3) Buchanan, J. \& Gardiner, L. (2003). A comparation of two reference point methods in multiple objective mathematical programming. European Journal of Operational Research, 149, 17-34.

(4) Cardoso, R.; Gomes, C.F.S.; Valle, R.; Nunes, K.R.A. \& Xavier, L.H. (2004). Multiple criteria decision making and environmental management through THOR system assessment: plastic material waste destination and performance evaluation of Brazilian construction and demolition waste recycling facilities - case studies. Anais do XXXVI SBPO, São João del Rei, 1054-1064.

(5) Chen, J. \& Lin, S. (2003). An interactive neural network-based approach for solving multiple criteria decision making problems. Decision Support Systems, 36, 137-146.

(6) Choo, E.U. \& Wedley, W.C. (2004). A common framework for deriving preference values from pairwise comparison matrices. Computers \& Operations Research, 31, 893-908.

(7) Dias, L.M.C. (2000). A Informação Imprecisa e os Modelos Multicritério de Apoio à Decisão - Identificação e uso de conclusões robustas. Tese de Doutorado, Faculdade de Economia, Universidade de Coimbra, 2000.

(8) Gomes, C.F.S. \& Gomes, L.F.A.M. (1996). Aplicação da Teoria dos Conjuntos Aproximativos à Modelagem Analítica de Apoio à Negociação. In: Anais do VIII CLAIO - Latin-Iberian-American Congress on Operations Research and Systems Engineering e XXVIII Simpósio Brasileiro de Pesquisa Operacional, Rio de Janeiro, v.II, 866-871.

(9) Gomes, C.F.S.; Gomes, L.F.A.M. \& Moreira, A.M.M. (1998). Modelos Analíticos para Negociação. Revista Pesquisa Naval, 11, 151-157.

(10) Gomes, C.F.S. (1999). THOR. Um Algoritmo Híbrido de Apoio Multicritério à Decisão para Processos Decisórios com Alternativas Discretas. Tese de Doutorado, Engenharia de Produção, COPPE-UFRJ. 
(11) Gomes, C.F.S. \& Gomes, L.F.A.M. (1999). Uma Aplicação de Conjuntos Aproximativos ao Apoio Multicritério à Negociação. Revista Pesquisa Naval, 12, 263-270.

(12) Gomes, C.F.S. \& Gomes, L.F.A.M. (2003). Modelagem Analítica para Negociação. Revista Marítima Brasileira. Rio de Janeiro, 123, 125-134, jul/set.

(13) Gomes, C.F.S. \& Gomes, L.F.A.M. (2004). Modelagem de Aspectos Qualitativos do Processo de Negociação. Revista de Administração Mackenzie, São Paulo, Ano 5, número 1, 83-104.

(14) Gomes, C.F.S. (2005). Using MCDA Methods THOR in an Application for Outranking the Ballast Water Management Options. Revista Pesquisa Operacional, 25, 11-28.

(15) Gomes, C.F.S. \& Gomes, L.F.A.M. (2005). Modelagem analítica dos principais aspectos qualitativos da negociação. Revista de la Escuela de Perfeccionamiento en Investigacion Operativa, Buenos Aires, 25, 97-116, novembro.

(16) Gomes, L.F.A.M. (1991). Conflito e Negociação no Planejamento Participativo: Uma Formulação de Análise de Decisões com Múltiplos Critérios. Revista Investigacion Operativa, 2(2), 111-119, dezembro.

(17) Gomes, L.F.A.M.; Gomes, C.F.S. \& Teixeira, A. (2002). Tomada de Decisão Gerencial o Enfoque Multicritério. Editora Atlas, São Paulo.

(18) Halpern, J. \& Chu, F. (2001). On the Np Completeness of finding an optimal strategy in games with common payoffs. Game Theory Journal, 99-106.

(19) Hipel, K.W. \& Fraser, N.M. (1984). Conflict Analysis Models and Resolutions. NorthHolland Series in System and Engineering, series, volume 11.

(20) Jelassi, T.; Kersten, G. \& Zionts, S. (1990). An introduction to Group Decision and Negotiation Support. In: Readings in Multiple Criteria Decision Aid [edited by C.A. Bana e Costa], Springer-Verlag, Berlin, 537-568.

(21) Kweku-Muata, O.-B. (2004). Evaluation of decision trees: a Multicriteria approach. Computers \& Operations Research, 31(11), 1933-1945.

(22) Leya-López, J.C. \& Fernandez-González, E. (2003). A new method for group decision support based on ELECTRE III methodology. European Journal of Operational Research, 148, 14-27.

(23) Lieberman, G.J. \& Hillier, F.S. (1988). Introdução à Pesquisa Operacional. $3^{\text {a }}$. edição. Editora Campus, São Paulo.

(24) Mármol, A.M.; Puerto, J. \& Fernández, F.R. (2002). Sequential incorporation of imprecise information in multiple criteria decision processes. European Journal of Operational Research, 137, 123-133.

(25) Matsatsinis, N.F. \& Samaras, A.P. (2001). MCDA and preferences disagregation in group decision support systems. European Journal of Operational Research, 130, 414-429.

(26) Moreira, A.M. \& Gomes, L.F.A.M. (1995). O processo de Negociação: Metáfora e Realidade. In: Anais do XXVII Simpósio Brasileiro de Pesquisa Operacional, Vitória. 
(27) Moreira, A.M. (1998). Os Sistemas de Apoio à Decisão em Grupo e os Modelos Multicritério: Uma nova Proposição de Interação nas Decisões em um Ambiente Globalizado. Tese de Doutorado, PUC-RJ, maio.

(28) Nunes, K.R.A.; Gomes, C.F.S. \& Valle, R. (2003). Centrais de Reciclagem de RCD implantadas no Brasil: Uso da Metodologia THOR para avaliar desempenhos. In: Anais do Simpósio de Pesquisa Operacional e Logística da Marinha - 2003, Rio de Janeiro.

(29) Osborne, M. \& Rubinstein, A. (1994). A Course in Game Theory. MIT Press, Boston.

(30) Pawlak, Z. (1982). Rough Sets. International Journal of Information \& Computer Sciences, 11, 341-356.

(31) Pawlak, Z. (1996). Rough Sets Present state and Perspectives. In: Proceedings of Information Processing and Management of Uncertainty in Knowledge-Based Systems, IPMU 96, III, 1137-1145, Granada, Espanha, July.

(32) Slowinski, R.; Salvatore, G. \& Benedetto, M. (1995). Rough Set Approach to MultiAttribute Choice and Ranking Problems. ICS Research Report 38.

(33) Slowinski, R.; Salvatore, G. \& Benedetto, M. (1996). Rough Approximation of a Preference Relation by Dominance Relations. ICS Research Report 16.

(34) Souza, F.M.C. (2002). Decisões Racionais em Situações de Incerteza. Editora Universitária UFPE.

(35) Steur, R.E. \& Na, P. (2003). Multiple criteria decision making combined with finance: a categorized bibliographic study. European Journal of Operational Research, 150, 496-515.

(36) Takeda, E. (2001). A method for multiple pseudo-criteria decision problems. Computers \& Operation Research, 28, 1427-1439.

(37) Von Neuman, J. \& Morgenstern, O. (1953). Theory of Games and Economic Behavior. $3^{\text {rd }}$ ed., Princeton University Press, Princeton, NJ.

(38) Whinston, M.D. \& Mas-Colell, A. (1995). Microeconomic Theory. Oxford University Press.

(39) Xavier, L.H.; Gomes, C.F.S.; Valle, R. \& Cardoso, R. (2004). Sistema de Apoio à Decisão Multicritério THOR aplicado na avaliação das alternativas de destinação de resíduo plástico. In: Anais do Simpósio de Pesquisa Operacional e Logística da Marinha - 2004, Rio de Janeiro.

(40) Yonn, K.P. \& Hwang, C.-L. (1995). Multiple Attribute Decision Making - An Introduction. Series: Quantitative Applications in the Social Sciences. Sage Publications.

(41) Zadeh, L.A. (1965). Fuzzy Sets. Information and Control, 8, 338-353.

(42) Zadeh, L.A. (1978). Fuzzy sets as a basis for theory of possibility. Fuzzy Sets and Systems, 1, 3-28.

(43) Zaras, K. (2004). Rough approximation of a preference relation by a multi-attribute dominance for deterministic, stochastic and fuzzy decision problems. European Journal of Operation Research, 159(1), 196-206. 
(44) Zhang, W. \& Yang, H. (2001). A study of the weighting method for a certain type of multicriteria optimisation problem. Computers \& Structures, 79, 2741-2749.

(45) Zhang, Q.; C. Jason, C.H. \& Chong, P.P. (2004). Decision consolidation: criteria weight determination using multiple preferences formats. Decision Support Systems, 38(2), 247-258.

(46) Zopounidis, C. \& Doumps, M. (2002). Multicriteria classification and sorting methods: a literature review. European Journal of Operational Research, 138, 229-246. 